\title{
CENÁRIOS PROSPECTIVOS E ATORES SOCIAIS: O DESENVOLVIMENTO HUMANO E SOCIAL
}

Ivan Marcio Gitahy Junior

Universidade do Oeste Paulista - UNOESTE, Curso de Administração e Recursos Humanos. Presidente Prudente, SP. Senac Presidente Prudente pós graduação em Administração.e Negócios. E-mail: ivan@unoeste.br

\section{RESUMO}

Com o intuito de discutir oportunidades e ameaças, pontos fortes e fracos relacionados ao dinamismo de uma determinada região faz-se necessário estudo sobre cenários, considerando um olhar humano. Assim, a presente pesquisa tem como objetivo gerar e analisar cenários prospectivos para o Município de Marília até 2027 a partir da visão de atores sociais. Para a realização desta pesquisa tomar-se-á como metodologia o Método Grumbach. Com essa metodologia de pesquisa será possível, além de se elaborar cenários, identificar quais deles serão mais motrizes e dependentes e como se comportarão na matriz dos impactos cruzados. Quanto maior o grau de dependência maior a probabilidade da ocorrência sofrer influência dos demais eventos. Com o exposto, tal pesquisa busca compreender e contextualizar o Município de Marília a luz de seu planejamento mais humano, considerando a participação de atores sociais locais.

Palavras-chave: Cenários. Planejamento. Recursos Humanos. Gestão.

\section{PROSPECTIVE SCENARIOS WITH SOCIAL ACTORS: HUMAN AND SOCIAL DEVELOPMENT}

\begin{abstract}
In order to discuss opportunities and threats, strengths and weaknesses related to the dynamism of a given region, it is necessary to study scenarios considering a human perspective. Thus, the present research aims to generate and analyze prospective scenarios for the Municipality of Marilia until 2027 from the perspective of social actors. To carry out this research, the Grumbach Method will be used as methodology. With this research methodology it will be possible, besides elaborating scenarios, to identify which ones will be more driving and dependent and how they will behave in the matrix of cross impacts. The greater the degree of dependence the greater the probability of occurrence to be influenced by the other events. With the above, this research seeks to understand and contextualize the Municipality of Marilia SP in light of its more human planning, considering the participation of local social actors.

Keywords: Scenarios. Planning. Human Resources. Management.
\end{abstract}

\section{INTRODUÇÃO}

Os estudos prospectivos representam uma importante ferramenta para discutir oportunidades e riscos quanto ao planejamento estratégico e gestão de um dado Município. O cenário da pesquisa será o Município de Marília, denominada Capital da Alta Sorocabana. Últimos dados da Fundação Seade, datado de 2017, o Município de Marília conta com uma área de $560,64 \mathrm{~km} 2$, a sua densidade demográfica (habitantes por $\mathrm{km} 2$ ) é de 387,57 e o grau de urbanização é de $97,96 \%$.
Acredita-se que além da relevância social e empresarial que os resultados da presente pesquisa podem trazer a Marília, também haverá uma ampliação teórica e empírica dos estudos sobre o método de cenários prospectivos pode auxiliar na compreensão de um dado Município paulista. A fim de entender melhor o que se busca com o trabalho, será apresentado o referencial teórico sobre cenários prospectivos e alguns conceitos de desenvolvimento e crescimento. Com a pesquisa de campo, ter-se-á uma análise dos 
cenários prospectivos do Município de Marília até o ano de 2027.

Segundo os autores Khan e Wierner (1967), a preocupação com o futuro liga-se a cinco fatores de interesse, ou seja: o lucro; a taxa de mudança; a necessidade filosófica, ou seja, o desejo de saber para onde ir; as questões militares, para onde iria o mercado bélico e o modismo do futuro. Seja qual for o fator que impulsiona o conhecimento do futuro, o homem acredita que estudar cenários pode auxiliar a encontrar as respostas desejadas.

Os métodos de construção de cenários tiveram como objetivo apresentar alternativas que levem a prospecções, buscando destacar não só tendências e ocorrências dominantes, mas também a possibilidade de transformação do ambiente. Tais estudos, segundo Amara (1988) e Coates, Mahaffie e Hines (1994) apresentam uma natureza exploratória e uma abordagem interdisciplinar na pesquisa sobre os rumos e as possibilidades do futuro.

O termo cenário caracteriza-se por um estudo criativo sobre uma situação futura utilizando uma metodologia própria, onde a construção de respostas está diretamente ligada às transformações que ocorrem no ambiente.

Para Porter (1989), os cenários podem ser entendidos como um conjunto de suposições plausíveis sobre as incertezas que podem influenciar o objeto de prospecção sempre com uma visão consistente sobre a realidade vindoura. Usando as próprias palavras de Porter temos o conceito

Cenários são uma visão internamente consistente da realidade futura, baseada em conjunto de suposições plausíveis sobre as incertezas que podem influenciar $o$ objeto de prospecção (PORTER, 1989, p. 15)

Segundo Amaral Filho (1996), desenvolvimento deve ser pensado a partir dos próprios atores sociais locais e é a eles que vamos dar voz a fim de se entender o cenário atual e de prospecção do objeto de pesquisa, ou seja, o Município de Marília.
Aliando as bases teóricas de cenários prospectivos a presente pesquisa além de se justificar socialmente, pois o planejamento estratégico do Município de Marília pode ter mais subsídios com os cenários prospectivos de desenvolvimento, justifica-se cientificamente tendo em vista que na área acadêmica não há estudos sobre a questão da prospecção do desenvolvimento do Município de Marília a partir dos atores sociais.

Cabe salientar que o desenvolvimento da pesquisa foi realizado dentro dos padrões éticos de acordo com a resolução 466/2012 do Conselho Nacional de Saúde/ Ministério da Saúde. Desta forma o projeto de pesquisa foi apreciado por Comitê de Ética e cadastrado na Plataforma Brasil, base nacional e unificada de registros de pesquisas envolvendo seres humanos, sendo aprovado e recebendo o CAAE $n^{\circ}$ 30979014.1.0000.5515.

A partir do exposto, a presente pesquisa teve como objetivo gerar e analisar cenários prospectivos para o Município de Marília até 2027 a partir da visão de atores sociais na elaboração de eventos.

\section{METODOLOGIA}

Para a realização desta pesquisa tomou-se como metodologia o método Grumbach.

Com essa metodologia de pesquisa foi possível, além de se elaborar cenários, identificar quais deles serão mais motrizes e dependentes e como se comportarão na matriz dos impactos cruzados. Cabe lembrar que tal matriz permitiu o cálculo dos graus de motricidade e dependência onde, quanto maior for o grau de motricidade de um evento, maior influência terá ou não nas probabilidades dos outros eventos. Quanto maior o grau de dependência maior a probabilidade da ocorrência sofrer influência dos demais eventos.

A presente pesquisa desenvolveu-se em uma abordagem quali-quantiativa, tomando como principal locus de investigação, o Município de Marília. Desta maneira foi realizado um levantamento procurando identificar, neste ambiente, alguns atores sociais que pudessem auxiliar a pesquisa.

A escolha dos atores sociais entrevistados, moradores do Município de Marília, foi feita considerando o critério aceite em participar da 
pesquisa e ser do segmento governo municipal; empresariado; universidade; lideranças sociais e trabalhadores. De cada segmento serão entrevistados dois membros, totalizando cinco segmentos e dez entrevistados. Os contatos dos atores sociais serão obtidos por meio de pesquisa na rede mundial de computadores. Dos resultados obtidos, far-se-á um primeiro contato com os possíveis entrevistados através de e-mail.

O referido e-mail fará menção à pesquisa e apresentará, aos respondentes, a importância do estudo.

Os dados coletados serão utilizados na construção dos cenários prospectivos sobre o tema da presente pesquisa. Segundo Godet (2000) a técnica de construção de cenários é realizada pela descrição coerente de uma situação fática e pelo encaminhamento imaginado e criado dos acontecimentos que permitem passar de uma situação de origem a uma situação futura.

A construção dos cenários prospectivos será baseada no método de Grumbach, formado por três elementos básicos:

- o decisor: pessoa que determinará a realização do estudo, que no caso da presente pesquisa será o pesquisador e o orientador.
- o gerente de controle: aquele que representa o setor, a área a ser estudada, com a responsabilidade de conduzir todo o processo.

- peritos: pessoas, normalmente externas ao sistema, que respondem às sucessivas consultas formuladas pelo gerente de controle. Como peritos inclui-se atores locais dos segmentos governo municipal; universidade; lideranças sociais e trabalhadores.

De acordo com Marcial e Grumbach (2008), com os cenários traçados e seus diversos acompanhamentos, tem-se uma visão sistêmica e alinhada, conseguindo compreender os acontecimentos. Segundo os autores citados, prever o futuro não é objetivo dos estudos prospectivos, mas sim estudar as diversas possibilidades de futuros plausíveis.

Comungando de tal filosofia, a construção de cenário auxiliará nos desdobramentos das incertezas e buscará compreender e contextualizar - Município de Marília a luz do planejamento, desenvolvimento e de seu crescimento considerando a participação de atores sociais locais. 
Quadro1. Roteiro semiestruturado da entrevista

\begin{tabular}{|c|c|c|c|c|}
\hline ÚBLICO & DS & INO & OPULAÇÃO & CIAIS \\
\hline $\begin{array}{l}\text { - Como está o } \\
\text { índice de emprego } \\
\text { e de desemprego } \\
\text { na indústria de } \\
\text { alimentos? } \\
\text { - Qual o grau de } \\
\text { desenvolvimento } \\
\text { do município? } \\
\text { - Percebe-se } \\
\text { mudanças no } \\
\text { desenvolvimento } \\
\text { de Marília? } \\
\text { Quantos projetos } \\
\text { destinam-se ao } \\
\text { mercado local? }\end{array}$ & $\begin{array}{l}\text { - Quantos projetos } \\
\text { destinam-se ao } \\
\text { mercado local? } \\
\text { - Qual a relação } \\
\text { com a lei de } \\
\text { incentivo a P\&D } \\
\text { (8248). } \\
\text { - Que relação há } \\
\text { entre o plano e o } \\
\text { desenvolvimento } \\
\text { de Marília? } \\
\text { - Qual } \\
\text { investimento feito } \\
\text { em mão de obra, } \\
\text { P\&D, tecnologia? } \\
\text { - Existe algum tipo } \\
\text { de parceria: } \\
\text { indústria, } \\
\text { universidade } \\
\text { governo? } \\
\text { - Qual a estrutura } \\
\text { organizacional da } \\
\text { empresa? }\end{array}$ & $\begin{array}{l}\text { - Há projetos: } \\
\text { pesquisa de } \\
\text { produtos, pesquisa } \\
\text { mercadológica, } \\
\text { consultoria } \\
\text { Empresa Junior. } \\
\text { - A Universidade } \\
\text { percebe de } \\
\text { movimento que } \\
\text { desenvolvimento } \\
\text { de Marília? De que } \\
\text { forma? } \\
\text { - Acredita em uma } \\
\text { participação mais } \\
\text { ativa da academia } \\
\text { neste processo. De } \\
\text { que forma? Com } \\
\text { P\&D, Tecnologia, } \\
\text { Capacitação? } \\
\text { - A universidade } \\
\text { recebe algum tipo } \\
\text { de incentivo para a } \\
\text { realização de } \\
\text { pesquisa? }\end{array}$ & 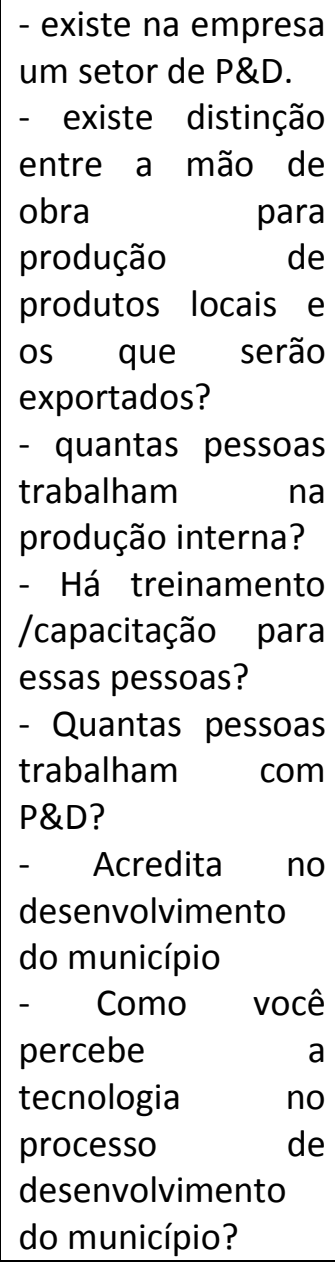 & $\begin{array}{l}\text { - Como percebe o } \\
\text { processo de } \\
\text { desenvolvimento do } \\
\text { Município? } \\
\text {-O Jornal, Clube, } \\
\text { Associaçãor tem } \\
\text { alguma participação } \\
\text { ou influência neste } \\
\text { processo? Gostaria } \\
\text { de ter? De que } \\
\text { forma? } \\
\text { - Que pontos } \\
\text { positivos e negativos } \\
\text { visualiza a partir } \\
\text { desse processo? } \\
\text { - Acredita que este } \\
\text { processo de } \\
\text { desenvolvimento do } \\
\text { Município permita } \\
\text { uma raior } \\
\text { visibilidade a região? } \\
\text { De que forma? }\end{array}$ \\
\hline
\end{tabular}

Fonte: Do autor

\section{RESULTADOS}

Ao realizar a pesquisa, o pesquisador gravou e transcreveu literalmente, tendo como foco a apresentação da matriz dos impactos cruzados, a matriz da motricidade e dependência, a geração e a interpretação dos cenários prospectivos para o Município de Marília, até 2027. Frisa-se que os mesmos foram gerados a partir da opinião dos peritos sobre a probabilidade de ocorrência dos eventos.

Cabe lembrar a matriz dos impactos cruzados representa o impacto da ocorrência ou não de um evento sobre a probabilidade de ocorrência dos demais. Considerando a probabilidade do evento ocorrer e, caso isso aconteça, qual o impacto que isso causaria na probabilidade de outro evento ocorrer. Tal matriz calcula o grau de motricidade e dependência de cada evento.

Para Marcial e Grumbach (2008), através da matriz da motricidade e dependência verifica-se quais eventos exercem maior e menor influência sobre os demais, ou seja, que eventos condicionam o sistema. Os eventos motrizes são definidos pela soma vertical e representam os eventos com mais influência sobre os demais.

Os cenários apresentados serão: mais provável, ideal e tendência. O cenário mais provável deve ser entendido com o resultado proveniente da opinião dos peritos caracterizando a aplicação do método Delphi. O cenário ideal deve ser entendido como o mais adequado, ou seja, o melhor para o Município de Marília objeto da pesquisa. O cenário de tendência representa um cenário prospectivo gerado, a partir do grupo de 
controle, considerando uma continuidade dos acontecimentos atuais sobre o futuro.

Tais cenários representam um panorama do Município de Marília considerando a retrospecção, a conjuntura atual e a prospecção para tal município, a partir da escolha de peritos, dos eventos que farão parte da pesquisa e do momento em que foi realizada a pesquisa. Esse conjunto de variáveis corroborou com os objetivos da pesquisa que é gerar e interpretar cenários prospectivos a luz do crescimento $\mathrm{e}$ desenvolvimento em um determinado horizonte temporal.

\section{DISCUSSÃO}

A visão desses atores sociais, seja ela retrospectiva e prospectiva, é o elemento chave para a geração de resultados, neste caso, a construção de cenários prospectivos. A participação deles recai em uma consulta para verificação de seus desejos sobre o futuro levandose em consideração convergências e divergência de opiniões sobre o passado. Somente a participação de atores sociais garante, ao cenário, legitimidade.

Moritz (2004), enfatiza que o futuro não depende apenas do passado ou da situação atual, mas também das estratégias dos atores sociais, onde o papel deles muitas das vezes é o de alterar a realidade à medida que viabilizam os projetos futuros.

A figura 01 representa o fluxo do processo de consulta às opiniões dos peritos, a partir do questionário apresentado a eles.

Figura 01. Fluxo da Informação da opinião dos peritos

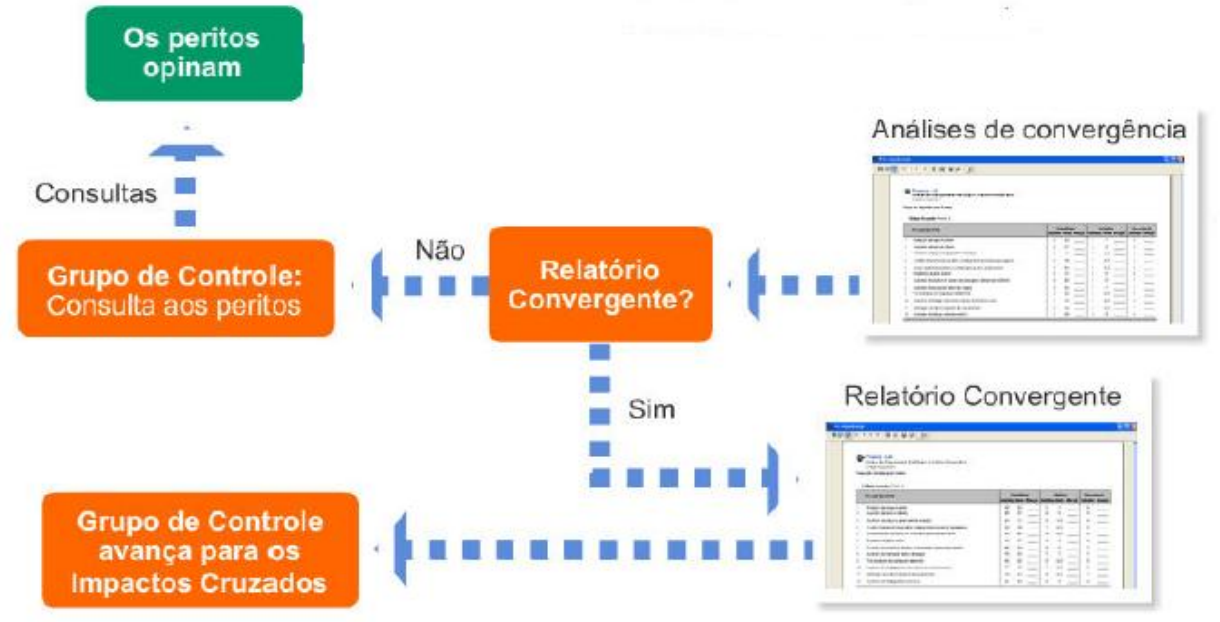

As informações circulam repetidas vezes pelo grupo de peritos. Caso haja uma convergência nas respostas gera-se um relatório de convergência, caso não ocorra convergência nesta fase inicial, faz-se uma nova consulta aos peritos que respondem novamente as mesmas questões até que a síntese dos resultados, a partir de análises de convergência, gere um relatório de convergência de opiniões. Essas rodadas acontecem até que um consenso ou quase consenso seja obtido.

Dando tal sequência submetida ao Método Grumbach, é capaz de gerar os seguintes cenários: o mais provável, o ideal, e o tendência.

\section{CONCLUSÃO}

O cenário mais provável acontecerá se todos os eventos ocorrerem, por ser entendido como o resultado proveniente da opinião dos peritos caracterizando a aplicação do método utilizado. O cenário ideal deve ser entendido como o mais adequado e acontecerá se não houver Crescimento populacional do Município de Marília, tendo sido identificado como medias e consequências, a favelização. $O$ cenário tendência ocorrerá caso o evento que menciona a Redução da taxa de analfabetismo da população adulta ocorrer, pois foi o evento que os peritos consideraram como um forte índice de crescimento e desenvolvimento. 
Tais cenários representam um panorama do Município de Marília considerando a retrospecção, a conjuntura atual e a prospecção para tal município, a partir da escolha de peritos, dos eventos que farão parte da pesquisa e do momento em que foi realizada a pesquisa. Esse conjunto de variáveis corroborou com os objetivos da pesquisa que foi gerar e interpretar cenários prospectivos a luz do crescimento e desenvolvimento em um determinado horizonte temporal.

\section{REFERÊNCIAS}

AMARA, R. What we have learned about forecasting and planning. Futures, v. 20, n. 4, p.385-401, 1988. https://doi.org/10.1016/00163287(88)90061-4

AMARAL FILHO, J. Desenvolvimento regional endógeno em um ambiente federalista. In: CARDOSO JR, J. C.; CUNHA, A. S. Planejamento e políticas públicas. Brasília, IPEA1996.

COATES, J. F.; MAHAFFIE, J. B.; HINES, A. Technological Forecasting: 1970-1993. Technological Forecasting and Social Change, v.47, p.23-33, 1994. https://doi.org/10.1016/00401625(94)90037-X.

GODET, M. A. Caixa de Ferramentas da Prospectiva Estratégica - Problemas e métodos. Lisboa: Cadernos do Centro de Estudos de Prospectiva e Estratégia, 2000.

GRUMBACH, R. J. S. Cenários Prospectivos - A Chave para o Futuro: Planejamento Estratégico. Rio de Janeiro: Catau, 2008.

KAHN, H. WIENER, A.J. The year 2000: a framework for speculation on the next thirty-three years. s/l: Hudson Institute, 1967

MARCIAL, E. C.; GRUMBACH, R. J. S. Cenários Prospectivos - Como Construir um Futuro Melhor. Rio de Janeiro: Ed. FGV, 2008.

MORITZ, Gilberto de Oliveira. Planejando por Cenários Prospectivos: a construção de um referencial metodológico baseado em casos. Tese de Doutorado, UFSC, CTC, PPEG, 2004.
PORTER, M. E. . Vantagem Competitiva. Rio de Janeiro: Campus, 1989.

Recebido para publicação em 10/05/2018

Revisado em 27/08/2018

Aceito em 04/09/2018 